\title{
Design of a structural equation model to evaluate the strategic prospective of SMEs.
}

\author{
Francisco Sánchez Rayas ${ }^{1}$
}

${ }^{1}$ Autonomous University of Queretaro, Mexico; francisco.sanchez@uaq.mx

\begin{abstract}
Queretaro is currently one of the states with the highest growth rate in the automotive industry. In the last five years, the number of companies has increased, reaching more than 300 small and medium-sized companies in the sector. However, they show a high degree of ignorance and lack of strategic foresight, which translates into poor planning in the short, medium and long term and low competitiveness, leading many of them to failure. This paper presents the results of a study within a strategic foresight evaluation with the development of a Structural Equation Model that allows the analysis of foresight and strategic planning within the automotive SMEs in the state of Queretaro. The study analyzes the necessary indicators to be evaluated and establishes the relationship of dependence between the variables, which is necessary to create the constructs of the model. It is confirmed that the adjustment of the model used is adequate for the evaluation of SMEs. The contributions of the research were: A theoretical contribution related to strategic foresight within SMEs and the construction of the structural equation model to evaluate strategic foresight in automotive SMEs in the state of Queretaro.
\end{abstract}

Keywords: Strategic Foresight Model; Structural Equations; Pymes

\section{Introduction}

In Mexico, the automotive industry represents one of the sectors with the greatest potential for development, so much so, that it is currently considered the second largest sector in the country's economy, and at the same time it is identified as a key sector in the generation of sources of employment and in the development of new strategies for the development and strengthening of the country's economy [1]. The National Institute of Statistics and Geography (INEGI) since 2017 points out in its reports the accelerated development of the automotive industry in Mexico, and the positive effect it has had on the search of new potential markets, and the consolidation of the economic system in various regions of the country, as well as the development of the business sector devoted to the automotive industry [2]. The state of Queretaro is a national benchmark for the development of small and medium-sized enterprises (SMEs) in the automotive sector, represented by more than 300 companies that are linked to global value chains and have a strong participation in foreign markets with the United States, Canada, Europe and Asia [3].

Thus, in $[4,5]$ it is pointed out that the automotive industry has evolved in recent years facing various challenges in business and competitiveness in production processes with the use of new technologies. The industry is based on basic principles such as production flow control, quality control and efficiency.

In the case of Mexico, the situation of the automotive industry behaved in an unstable manner during the first two quarters of this year, presenting a mixed crisis situation, mainly represented by an economic crisis and a sanitary crisis, both generated by the current SARS-CoV-2 (Covid-19) sanitary emergency. The aforementioned, caused production to be paralyzed and exports in this area to decrease; data show that this situation led to a decrease in production of about $40 \%$, while exports were affected with a decrease of more than $41 \%$; which can be considered as a very unfavorable scenario for the sector 
and the country, if we take into account the impact of the automotive sector in the dynamics and economic structure of the country [6].

While in Latin America, the Economic Commission for Latin America and the Caribbean (ECLAC) points out that one of the most important sectors is the automotive sector, because it favors the transformation, differentiation and distribution of production in the countries of the region. In addition, it improves local capacities, is a source of employment and enables the creation of productive chains at the local and regional level [7].

In this sense, in recent years this sector has shown a greater degree of investment, mainly in countries such as Mexico and Brazil, increasing production and at the same time, exports to Central America and Europe. Figure 1. Shows production per type of vehicle in the main countries of the automotive sector in Latin America.

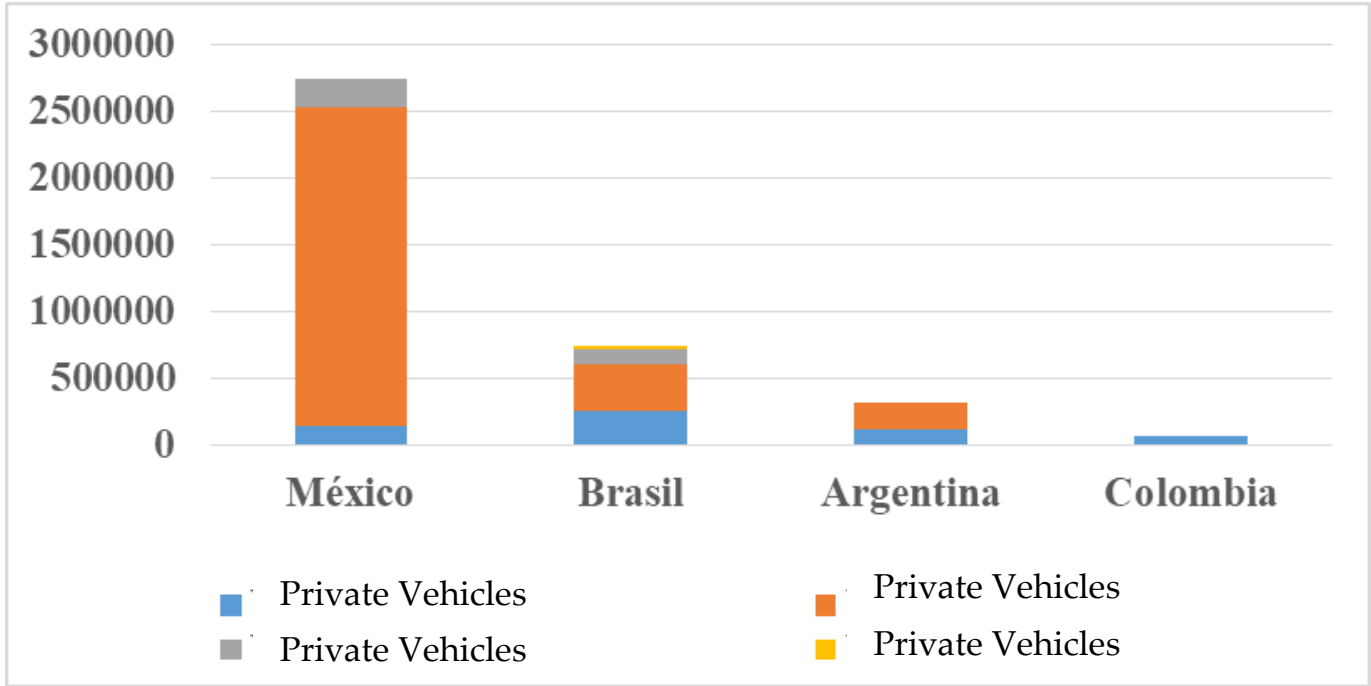

Figure 1 . Number of vehicles produced by main countries of the automotive industry in Latin America, 2019.

The automotive sector in Queretaro has been part of the state's industrial development process, so much so, that since 2003 the sector has shown a growth in its impact on the state's gross value added (GVA) $[8,9]$. This is due, to the investment and interest of several companies to establish themselves in the state, which led to a greater dynamism in the sector, reaching more than $20 \%$ of the total investments made in the state.

Currently, the state has about 316 companies within the automotive industry, which in most cases have been affected by the shutdown of the automotive industry due to the current health crisis, so that production has been reduced by $70 \%$ of production capacity. It is expected that the recovery process will be slow and that by the end of 2020 production will reach about $80 \%$ of the production prior to the beginning of the pandemic, the forecast is that by the year 2023, the maximum production capacity in the sector will be reached.

In relation to strategic foresight, through different researches [10-13] strategic planning is defined as a management and decision-making tool where managers define the strategic objectives and goals to be achieved in the long term. In other words, strategic foresight consists of anticipating the future, taking into account current events, which allows for the study of possible scenarios and the adoption of strategies to fulfill the vision proposed by the company.

In spite of this, trends may not be favorable, however, the prospective makes it easier to take corrective actions to minimize the possible effects; if the scenario is optimistic, the company's position is maintained.

In view of the above, it is necessary for SMEs to have an adequate strategic foresight that allows them to foresee the medium and long term in order to avoid possible failures. In the case of SMEs in the automotive sector, this is of vital importance, since they generate more than $15 \%$ of the sources of employment and close to $20 \%$ of the total production of 
the manufacturing industry. By analyzing the above data, it is necessary to achieve the insertion of SMEs in the dynamics of large companies in the automotive industry, which will allow the development of strategies to expand their future production and achieve trade openness [14].

Based on this premise, the objective of this research is to develop a structural equation model (SEM) that makes it possible to evaluate the strategic prospective in the SMEs of the automotive sector in the state of Queretaro, as well as the dimensions that compose it, conceiving an integral perspective of the company. Probabilistic sampling was used to determine the number of surveys to be applied to the total sample of SMEs. The research is based on the selection by a group of experts of the indicators involved in strategic foresight. The study focuses on obtaining the SEM model that allows the evaluation of strategic foresight. To conclude, the evaluation indicators of the model adjustment were analyzed to determine if it is correct and adequate to evaluate the strategic foresight of the automotive SMEs.

The article is divided as follows: the first part corresponds to the introduction, where the objective of the research is presented, the second part is the materials and methods, where the methodology applied in the research is defined, then the results obtained are shown and conclusions are reached to respond to the objective of the research, and the article ends with the bibliographical references used in the research.

\section{Materials and Methods}

In the particular case of this study, the process of selection and validity of the variables was through experts. The following considerations were taken into account for the selection of the specialists: foresight.

- To be an academic or practical expert related to the study of strategic planning and

- To present a broad knowledge of the area of study of SMEs.

In summary, 10 experts were selected who met the required profile, 5 dimensions were identified from the analysis of the experts, and 25 variables were selected for the study (see table 1).

Next, a cross-sectional study was carried out by means of a survey in which 325 people related to strategic foresight within the automotive SMEs in Queretaro participated, which facilitated the analysis and construction of the model with the SPSS 24 program, AMOS 24, which allows the construction of the Structural Equations Model. 
Table 1. Dimensions and variables selected for the analysis.

\begin{tabular}{lll}
\hline Abbreviation & Dimensions & \multicolumn{1}{c}{ Variables or indicators } \\
\hline INV & & Investment \\
COST & Costs \\
FINC & Economic- & Financing \\
RENT & Financial & Profitability \\
IMP & & Tax \\
PLAN & & Planning \\
SCLT & & Customer Satisfaction \\
PVENT & & Sales Policy \\
OMERC & Marketing & Market Orientation \\
RCLTPV & & Customer-Supplier Relationship \\
EPROD & & Product Strategy \\
PAMB & & Environmental Policy \\
MDESC & Environmental & Waste Management \\
EMBI & Environmental Strategy \\
CAMB & & Training and Environmental Awareness \\
LOG & & Logistics \\
TIC & & Information Technologies \\
CALID & Technological & Quality Certification \\
CINNOV & & Innovation Capability \\
CTECN & & Technological Capacity \\
CLAB & & Work Climate \\
GHUM & & Human Resources \\
CAPAD & Resources & Training and Education \\
CORG & Organizational Culture \\
SREC & & Selection and Recruitment \\
& &
\end{tabular}

For the construction of the database, respondents were asked whether: Is there an influence on the relationship between variable k with strategic foresight?

A Likert scale was used with the following criteria:

1. $\quad$ No influence (1)

2. Very little influence (2)

3. $\quad$ Little influence (3)

4. Moderately influential (4)

5. Strong influence (5)

6. $\quad$ Very strong influence (6)

7. Potentially influential (7)

On the other hand, the SEM model approach is a multivariate statistical technique that is used for data analysis, SEM allows to establish relationships and dependence between variables and it is about forming linear equations to determine which ones are independent or dependent $[15,16]$. The following model was proposed for this analysis: 


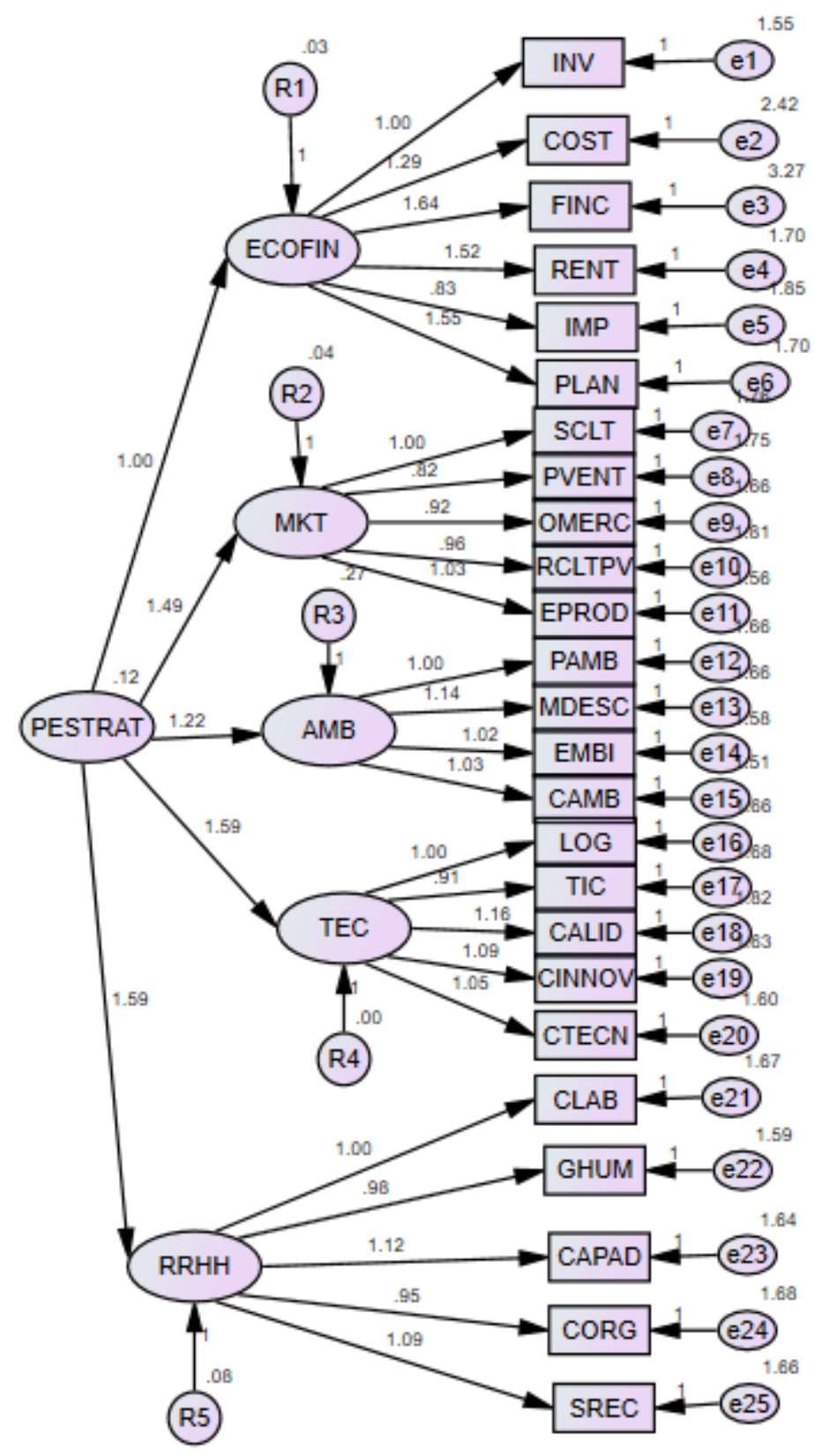

Figure 2. Model for strategic foresight evaluation.

\section{Results}

The descriptive analysis of the sample is presented in Table 2. It can be seen that high mean values were obtained, which represent a strong influence of the variables within the strategic foresight of the SMEs, the lowest mean was that of financing, which is a moderately influential variable. 


\begin{tabular}{lcccc}
\hline \multicolumn{1}{c}{ Variables } & Mean & Median & $\begin{array}{c}\text { Standard } \\
\text { Deviation }\end{array}$ & Variance \\
\hline Investment & 5.66 & 6.00 & 1.304 & 1.700 \\
Costs & 4.86 & 5.00 & 1.634 & 2.671 \\
Financing & 4.27 & 4.00 & 1.914 & 3.664 \\
Profitability & 5.20 & 5.00 & 1.428 & 2.039 \\
Tax & 5.11 & 5.00 & 1.399 & 1.958 \\
Planning & 5.20 & 5.00 & 1.433 & 2.052 \\
Customer Satisfaction & 5.37 & 6.00 & 1.434 & 2.057 \\
Sales Policy & 5.12 & 5.00 & 1.397 & 1.952 \\
Market Orientation & 5.18 & 5.00 & 1.382 & 1.910 \\
Customer-Supplier Relationship & 5.15 & 5.00 & 1.444 & 2.084 \\
Product Strategy & 5.16 & 5.00 & 1.370 & 1.876 \\
Environmental Policy & 4.98 & 5.00 & 1.453 & 2.111 \\
Waste Management & 4.95 & 5.00 & 1.496 & 2.239 \\
Environmental Strategy & 4.96 & 5.00 & 1.428 & 2.039 \\
Training and Environmental Awareness & 5.01 & 5.00 & 1.409 & 1.986 \\
Logistics & 5.18 & 5.00 & 1.401 & 1.964 \\
Information Technologies & 5.05 & 5.00 & 1.388 & 1.928 \\
Quality Certification & 5.15 & 5.00 & 1.493 & 2.229 \\
Innovation Capability & 4.99 & 5.00 & 1.412 & 1.994 \\
Technological Capacity & 5.08 & 5.00 & 1.390 & 1.933 \\
Work Climate & 5.03 & 5.00 & 1.431 & 2.048 \\
Human Resources & 5.07 & 5.00 & 1.397 & 1.952 \\
Training and Education & 5.11 & 5.00 & 1.455 & 2.117 \\
Organizational Culture & 5.04 & 5.00 & 1.420 & 2.016 \\
Selection and Recruitment & 5.09 & 5.00 & 1.454 & 2.113 \\
\hline
\end{tabular}

In a second step, the robustness and stability of the data were analyzed through the reliability analysis evaluated by Cronbach's alpha, this coefficient, according to [17], is a quick and reliable way to validate the model and as a metric that weights the existing correlation between the variables that compose it. In [18] it is mentioned that a good value of fit and consistency of Cronbach's alpha is between 0.70 and 0.90 . In the study, an alpha value of 0.779 was obtained, which means a good fit, the result is shown in Table 3 .

Table 3. Reliability statistics

\begin{tabular}{ccc}
\hline Cronbach's alpha & $\begin{array}{c}\text { Cronbach's alpha based on } \\
\text { standardized elements }\end{array}$ & $\begin{array}{c}\text { Number of } \\
\text { elements }\end{array}$ \\
\hline .779 & .781 & 25 \\
\hline
\end{tabular}

The study of the existing analytical relationships between the variables obtained a significant Chi-Square value, obtaining a value of 492.764 ( $\mathrm{DF}=170, \mathrm{p}$-value $<0.05)$. Therefore, the model can be considered valid in the first instance [19].

Table 4. Model fit index 


\section{\begin{tabular}{|r|r|}
\hline \multirow{3}{*}{ the $\quad$\begin{tabular}{|r|} 
Chi-square $=492.764$ \\
Degrees of freedom $=270$ \\
Probability level $=.001$ \\
As a comple- \\
ment to the analysis, \\
significance of the
\end{tabular}}
\end{tabular} variables is obtained and their estimated values are high, indicating a good fit of the var- iables to the proposed model (The meaning of "***" indicates that it is valid for significance levels of $0.01,0.05$ and 0.1 ), the results are shown in Table 5 .}

Table 5. Estimated values and significance of the variables

\begin{tabular}{|ccc|cccc|}
\hline & & & Estimate & S.E. & C.R. & P \\
\hline ECOFIN & $<--$ & PESTRAT & 1.000 & & & \\
MKT & $<--$ & PESTRAT & 1.490 & .335 & 4.443 & $* * *$ \\
AMB & $<--$ & PESTRAT & 1.219 & .282 & 4.324 & $* * *$ \\
TEC & $<--$ & PESTRAT & 1.589 & .349 & 4.550 & $* * *$ \\
RRHH & $<--$ & PESTRAT & 1.592 & .346 & 4.596 & $* * *$ \\
INV & $<---$ & ECOFIN & 1.000 & & & \\
COST & $<---$ & ECOFIN & 1.293 & .317 & 4.072 & $* * *$ \\
FINC & $<--$ & ECOFIN & 1.638 & .387 & 4.233 & $* * *$ \\
RENT & $<--$ & ECOFIN & 1.515 & .327 & 4.631 & $* * *$ \\
IMP & $<--$ & ECOFIN & .833 & .242 & 3.449 & $* * *$ \\
PLAN & $<--$ & ECOFIN & 1.547 & .332 & 4.661 & $* * *$ \\
SCLT & $<--$ & MKT & 1.000 & & & \\
PVENT & $<---$ & MKT & .822 & .167 & 4.930 & $* * *$ \\
OMERC & $<--$ & MKT & .916 & .173 & 5.303 & $* * *$ \\
RCLTPV & $<--$ & MKT & .957 & .180 & 5.301 & $* * *$ \\
EPROD & $<--$ & MKT & 1.032 & .181 & 5.686 & $* * *$ \\
PAMB & $<--$ & AMB & 1.000 & & & \\
MDESC & $<---$ & AMB & 1.136 & .181 & 6.259 & $* * *$ \\
EMBI & $<--$ & AMB & 1.017 & .167 & 6.092 & $* * *$ \\
CAMB & $<---$ & AMB & 1.032 & .167 & 6.169 & $* * *$ \\
LOG & $<--$ & TEC & 1.000 & & & \\
TIC & $<---$ & TEC & .909 & .164 & 5.553 & $* * *$ \\
CALID & $<---$ & TEC & 1.157 & .189 & 6.114 & $* * *$ \\
CINNOV & $<---$ & TEC & 1.092 & .179 & 6.107 & $* * *$ \\
CTECN & $<--$ & TEC & 1.046 & .174 & 6.018 & $* * *$ \\
CLAB & $<--$ & RRHH & 1.000 & & & \\
GHUM & $<--$ & RRHH & .977 & .157 & 6.235 & $* * *$ \\
CAPAD & $<--$ & RRHH & 1.121 & .171 & 6.569 & $* * *$ \\
CORG & $<--$ & RRHH & .946 & .156 & 6.062 & $* * *$ \\
SREC & $<---$ & RRHH & 1.093 & .169 & 6.486 & $* * *$ \\
\hline & & & & & &
\end{tabular}


Finally, an analysis is made of the goodness-of-fit indicators that define whether the construct is adequate to carry out evaluations of the strategic foresight of SMEs and the degree of relevance of the variables in the analysis of strategic foresight. In the case of the CMIN/DF, a value of 1.084 was obtained, according to [20-22], which is considered a good fit value at values below 3 , the result in this research is good. The mean square error (RMR) index was also evaluated, which measures the variances and covariances of the sample and whether these differ from the estimates obtained, in researches such as that of [23-25] a good result is considered the closer the values are to zero, in the present research a value of 0.077 was obtained. Therefore, the RMR estimates obtained are good, another very important indicator is the goodness of fit index (GFI), it takes values between 0 and 1, authors such as $[26,27]$ express that the closer to 1 , the better goodness of fit the model will have, in the case study a GFI $=0.959$ was obtained, which represents an excellent value of fit of the model so it is reliable to use it for the evaluation of strategic foresight. Other indicators obtained for the model fit are the normalized fit index (NFI) which includes the number of degrees of freedom of the model analyzed, which reaches a value of 0.911 , with values higher than 0.9 considered as good [28, 29], another one is the RMSEA (Root Mean Square Error of Approximation) that reaches a value of 0.013 , which is lower than the significance level of 0.05 , and therefore evidences a good fit of the overall model [30]. The results can be seen in table 6 .

Table 6. Goodness-of-fit values

\begin{tabular}{|c|cccc|}
\hline Model & RMR & GFI & NFI & RMSEA \\
\hline Default model & .077 & .959 & .911 & .013 \\
Saturated model & .000 & 1.000 & 1.000 & \\
Independence model & .269 & .698 & .00 & .082 \\
\hline
\end{tabular}

The model obtained has a good goodness of fit, and is optimal for strategic foresight analysis of the variables that comprise the strategic foresight.

\section{Conclusions}

1. Strategic foresight is an important element within SMEs as it allows the management of processes and products, it also helps to identify threats and opportunities that may arise in the long term, it helps to face new competencies in the market, as well as to identify trends in the international market and its insertion in the stock market of the large company.

2. The use of a Likert scale and reliability analysis made it possible to determine the Economic-Financial, Marketing, Environmental, Technological and Human Resources dimensions, which are suitable for measuring strategic foresight. These dimensions were complemented by a set of pertinent indicators to measure the dimensions of the strategic perspective, a construct that facilitated the evaluation and the formulation of strategies aimed at improving SME management.

3. The proposed model is based on the generally known definition of strategic foresight and, based on structural equations, it is adequate to evaluate this process in automotive SMEs and could even be generalized to other industries. The model fits perfectly into the perspective, and complies with the following assumptions: 1) Indicators at ordinal measurement level, 2) Indicators with a Likert scale of 7 criteria, higher than the established 4 criteria, 3) Inclusion of all relevant variables in the model, 4) A minimum sample of 325 individuals, which exceeds the requirements of the model, 5) A minimum of 5 indicators per dimension, higher than the methodological requirements, and 6) A total of 25 indicators, which is in the optimal range. 
1. Miranda, A. "The Automotive Industry in Mexico: Antecedents, current situation and perspectives", Accounting, Administration, no.221, pp. 209-246, January-April 2007. Available: https://doi.org/10.22201/FCA.24488410E.2007.726. [Google $\underline{\text { Scholar] }[\text { CrossRef] }}$

2. Gachúz, J. and Montes, M. "The Automotive Industry in Mexico and China", Latin American Journal of Trade Policy, vol. 3, no. 6, pp. 68-86, 2020. Available: doi:10.5354/0719-9368.2020.57168. [Google Scholar] [CrossRef]

3. "Automotive Industry, the Origin of Modern Queretaro", Informative Codex, 2020. [Online]. Available: https://codiceinformativo.com/codice economico/industria-automotriz-el-origen-del-queretaro-moderno/.[Accessed: 17- Dec- 2020].

4. Binder, A. "Automotive Industry I History, Overview, Definition, Developments, \& Facts", Encyclopedia Britannica, 2020. [Online]. Available: https://global.britannica.com/technology/automotive-industry. [Accessed: 17- Dec- 2020].

5. Buirma, T. "Basic Principles for Outsourcing in the Automotive Sector", Manufacturing, 2018. [Online]. Available: https://manufactura.mx/columnas/2018/04/02/principios-basicos-para-la-tercerizacion-en-el-sector-automotriz. [Accessed: 18- Dec- 2020].

6. Linares, J. " Mexico's Automotive Industry and the T-MEC: Challenges and Prospects ", in Critical and strategic factors in territorial interaction, current challenges and future scenarios. Vol. IV, Mexico City, National Autonomous University of Mexico and Mexican Association of Sciences for Regional Development A.C, 2020, pp. 180-183. [Online]. Available: http://ru.iiec.unam.mx/5217/1/1-035-Linares.pdf. [Google Scholar]

7. Economic Commission for Latin America and the Caribbean (ECLAC), "Foreign Direct Investment in Latin America and the Caribbean"., Santiago de Chile, 2018. [Online]. Available: http://hdl.handle.net/11520/23425. [Google Scholar]

8. [8] S. Daville-Landero, " The Evolution of the Auto Parts Industry in Queretaro, 1993-2008", Economy, Society and Territory, 2012. Available: https://doi.org/10.22136/est00201266. [Google Scholar] [CrossRef]

9. Banda Ortiz, H., Gómez Hernández D. and Carrión Ruiz, L. "The Automotive Industry in Queretaro State: A Structural Change?", Scientific Journal Thinking \& Management, vol., no. 41, pp. 36-59, $2016 . \quad$ Available: https://doi.org/10.14482/pege.41.9719. [Google Scholar] [CrossRef]

10. Mejía Argueta, C., Agudelo I. and Soto Cardona, O. " Scenario Planning: A Case Study in a Logistics Consulting Company in Colombia ", Managerial Studies, vol. 32, no. 138, pp. 96-107, 2016. Available: https://doi.org/10.1016/j.estger.2015.12.004. [Google Scholar] [CrossRef]

11. [11] Mora-Riapira, E., Vera-Colina M. and Melgarejo-Molina, Z. "Strategic Planning \& Competitiveness Levels of MSMEs in the Commerce Sector in Bogota", Managerial Studies, vol. 31, no. 134, pp. 79-87, 2015. Available: https://doi.org/10.1016/j.estger.2014.08.001 . [Google Scholar] [CrossRef]

12. Hermanson, D., Tompkins, J. Veliyath R. and Ye, Z. "Strategic Planning Committees on U.S. Public Company Boards: Axiomatic or Paradoxical?", Long Range Planning, vol. 53, no. 5, p. 101967, 2020. Available: https://doi.org/10.1016/j.lrp.2020.101967. [Google Scholar] [CrossRef]

13. D. Ojha, P. Patel and S. Sridharan, "Dynamic Strategic Planning \& Firm Competitive Performance: A Conceptualization and an Empirical Test", International Journal of Production Economics, vol. 222, p. 107509, 2020. Available: https://doi.org/10.1016/j.ijpe.2019.09.030. [Google Scholar] [CrossRef]

14. Jiménez Bautista, S. and Rodríguez Peralta, C. " The Inclusion of SMEs in the Value Chain of the Automotive Industry in Mexico Within the Framework of The Trans-Pacific Partnership (ttp)", Economy Informs, vol. 403, pp. 46-65, 2017. Available: https://doi.org/10.1016/j.ecin.2017.05.004. [Google Scholar] [CrossRef]

15. Hussey, D. and Eagan, P. "Using structural equation modeling to test environmental performance in small and mediumsized manufacturers: Can SEM help SMEs?", Journal of Cleaner Production, vol. 15, no. 4, pp. 303-312, 2007. Available: https://doi.org/10.1016/j.jclepro.2005.12.002. [Google Scholar] [CrossRef]

16. Escandón Barbosa, D. and Hurtado Ayala, A. " Factors Influencing the Export Development of SMEs in Colombia", Managerial Studies., vol. 30, no. 131, pp. 172-183, 2014. Available: https://doi.org/10.1016/j.estger.2014.04.006. [Google Scholar] [CrossRef]

17. González Alonso, J., \& Pazmiño Santacruz, M. (2015). Calculation and Interpretation of Cronbach's Alpha for The Case of Validation of the Internal Consistency of a Questionnaire with Two Possible Likert-type Scales. Publicando Magazine, 2(1), 62-67., 2(1), 62-67. [Google Scholar]

18. Oviedo, H. C., \& Arias, A. C. (2005). Approach to The Use of Cronbach's Alpha Coefficient. Colombian Journal of Psychiatry, 34(4), 572-580. [Google Scholar]

19. Bollen, K. (1989): Structural Equations with Latent Variables. Wiley Series in Probability and Mathematical Statistic Ed. John Wiley and Sons, New York. [Google Scholar]

20. Hu L, Bentler P. Evaluating Model Fit. In: Hoyle R, Editor. Structural Equation Modelling: Concepts, issues and applications. Thousand Oaks, CA: Sage Publications: 1995.pp, (76-99). [Google Scholar]

21. Furlan, L. A., Heredia, D. E., Piemontesi, S. E., \& Tuckman, B. W. (2012). Confirmatory Factor Analysis of the Argentine Adaptation of the Tuckman Procrastination Scale (ATPS). Psychology Perspectives: Journal of Psychology and Related Sciences, 9(3), 142-149. [Google Scholar]

22. Saumeth, K. T., Barraza, F. M., Afanador, T. R., \& Ospino, L. S. (2013). A Look at Quality Management Models. Investigium IRE Social and Human Sciences Journal, 4(1), 216-233. [Google Scholar]

23. Covas Várela, D., Hernández Pérez, G. D., Cabello Eras, J. J., \& Crespo García, L. (2020). Structural Equation Model with Influential Variables in Urban Quality of Life. Case study: City of Cienfuegos, Cuba. Ingeniare. Chilean Journal of Engineering, 28(3), 499-513. [Google Scholar] [CrossRef] 
24. Huamaní, C. G. A., Sinisterra, O. O. L., Ruiz, E. B., \& Maldonado, S. I. M. (2020). Personal and Psychological Factors that Influence Entrepreneurial Intention in Students of the University of Panama. Lex: Journal of the Faculty of Law and Political Science of Alas Peruanas University, 18(25), 411-436. [Google Scholar] [CrossRef]

25. López, J. I. H., \& Calderón, A. R. C. (2020). Organizational Attractiveness: Influence of Image and Corporate Social Responsibility. Journal of Psychology and Behavioral Sciences of the Academic Unit of Legal and Social Sciences, 11(1), 112-125. [Google Scholar]

26. Palacios-Rodríguez, A., \& Illescas-Martínez, A. (2021). Psychometric and Technological Analysis of a Competency Assessment Test: The PIRLS Model Using Structural Equations. International Journal of Pedagogy and Educational Innovation,1(1), 37-68. [Google Scholar] [CrossRef]

27. Cortés, G. L. (2020). Analysis of The Perception of U.S. Visitors to Colombia: A Structural Equation Model. Studies and Perspectives in Tourism, 29(1), 51-71. [Google Scholar]

28. Lévy J. P., Varela J. Modeling with Covariance Structures in the Social Sciences. Madrid: Netbiblo; 2006. [Google Scholar]

29. Escobedo Portillo, María Teresa, Hernández Gómez, Jesús Andrés, Estebané Ortega, Virginia, \& Martínez Moreno, Guillermina. (2016). Structural Equation Models: Characteristics, Phases, Construction, Application and Results. Science \& Work,18(55), 16-22. https://dx.doi.org/10.4067/S0718-24492016000100004 [Google Scholar] [CrossRef]

30. Medrano, L. A., \& Muñoz-Navarro, R. (2017). Conceptual and Practical Approach to Structural Equation Modeling. Digital Journal of Research in University Teaching, 11(1), 219-239. [Google Scholar] [CrossRef] 